\title{
Escherichia coli J5: imunização de fêmeas bovinas leiteiras contra mastites causadas por Escherichia coli
}

\author{
Escherichia coli J5: immunization of dairy cows against Escherichia coli mastitis
}

\author{
Marianna Barbosa Gentilini ${ }^{*}$ Lívio Ribeiro Molina $^{\mathrm{I}}$ Elias Jorge Facury Filho \\ Gustavo Henrique Ferreira Abreu Moreira' ${ }^{I}$ Luiz Paulo Vilasboas Moreira ${ }^{I I}$ \\ Reuel Luiz Gonçalves ${ }^{\mathrm{II}}$ Antônio Ultimo de Carvalho ${ }^{\mathrm{I}}$
}

\section{- REVISÃO BIBLIOGRÁFICA -}

RESUMO

Neste trabalho, revisamos os principais aspectos ligados à mastite causada por coliformes, mais especificamente a Escherichia coli, com enfoque principal nos fatores de risco associados ao animal, bem como na utilização da vacina Escherichia coli J5 na imunização de fêmeas bovinas leiteiras. Os coliformes estão amplamente distribuídos no ambiente, assumindo especial importância em sistemas de criação em que a busca pela qualidade do leite mantém a contagem de células somáticas (CCS) em níveis inferiores a 150000 células $\mathrm{ml}^{-1}$. Nesse contexto, o período seco representa um momento de extrema importância na definição da ausência ou não de um quadro de mastite, decorrente da ação de patógenos ambientais no pós-parto imediato. A terapia para vacas secas frente a infecções por germes ambientais perde eficácia, sendo necessária a associação a outros métodos, como, por exemplo, a vacinação com Escherichia coli J5. A cepa J5, por possuir um antígeno nuclear relativamente exposto, é capaz de estimular a produção de imunoglobulinas que apresentam reação cruzada com antígenos nucleares de outras bactérias, resultando em uma imunidade contra uma variedade de gêneros e cepas bacterianas. Estudos demonstram que a vacinação com Escherichia coli J5 é capaz de reduzir a ocorrência, intensidade e duração de casos clínicos de mastite por Escherichia coli, sendo também observada uma maior produção de leite nos animais vacinados. Entretanto, ainda é controverso seu papel na redução da CCS.

Palavras-chave: gado de leite, vacina, glândula mamária, coliforme.

\section{ABSTRACT}

This paper aims to review the main aspects of coliform mastitis, specifically Escherichia coli, emphasizing the immunization of dairy cows with Escherichia coli J5 vaccine, as well as the animal risk factors. Coliforms are widespread in the environment and are of particular importance in farming systems in which the search for a greater milk quality guarantee low somatic cell counts $\left(<150,000\right.$ cells $\left.\mathrm{ml}^{-1}\right)$. The dry period is an extremely important moment that plays crucial role in the occurrence of mastitis caused by environmental pathogens during the immediate postpartum. The dry cow therapy against environmental infections has lost effectiveness leading to the need for the combination with other methods such as immunization with Escherichia coli J5 vaccine. Due to a relatively exposed nuclear antigen, the Escherichia coli strain J5 can stimulate the production of immunoglobulins that cross-react with nuclear antigens from other bacteria. It results in immunity against a variety of bacterial genres and strains. It has been shown that the use of Escherichia coli J5 vaccine can reduce the occurrence, intensity and duration of clinical cases of Escherichia coli mastitis, besides increase the production of dairy cows. However, its role in reducing milk SCC is still controversial.

Key words: dairy cattle, vaccine, mammary gland, coliform.

\section{INTRODUÇÃO}

As bactérias conhecidas como coliformes compreendem o grupo mais importante de microrganismos responsáveis pelos casos de mastite clínica ambiental. Com as mudanças nos sistemas de produção e a busca por melhorias na qualidade do leite, a mastite ambiental, principalmente aquela causada por coliformes, pode ultrapassar a mastite contagiosa em importância econômica. Essa tendência é atribuída à diminuição nas perdas de produção em rebanhos com baixa CCS e pelo aumento na quantidade de vacas, nesses rebanhos, com maior susceptibilidade à mastite por coliformes. Além disso, o aumento na

IDepartamento de Clínica e Cirurgia Veterinárias, Escola de Veterinária, Universidade Federal de Minas Gerais (UFMG), Avenida Antônio Carlos n.6627, CP 567, 30123-970, Belo Horizonte, MG, Brasil. E-mail: mgentilini_vet@yahoo.com.br. *Autor para correspondência.

"Biogénesis Bagó, Curitiba, PR, Brasil. 
densidade animal nos sistemas de produção resulta em maior exposição às bactérias (HOGAN \& SMITH, 2003). Os casos clínicos de mastite aguda, o descarte de leite, a ineficiência do tratamento com antibióticos e a alta taxa de mortalidade relacionada ao choque endotóxico são apontados como os fatores responsáveis pelo grande impacto econômico das mastites causadas por coliformes (WENZ et al., 2006).

A manifestação clínica da mastite por coliformes no início da lactação está intimamente relacionada com a ocorrência de novas infecções intramamárias (IMM) no período seco, sendo esses casos mais severos e associados ao período de imunossupressão. Observa-se que, em algumas circunstâncias, as concentrações de anticorpos no soro e no leite podem aumentar com o uso de vacinas contra coliformes, constituídas de microorganismos mutantes, tais como $\boldsymbol{E}$. coli J5. A vacinação é eficaz no aumento da resistência das vacas às infecções por coliformes no período pós-parto, reduzindo significativamente as perdas causadas por essa doença (BURVENICH et al., 2003).

Nesse contexto, o objetivo deste trabalho é revisar os principais aspectos ligados à mastite causada por coliformes, mais especificamente a Escherichia coli, com enfoque principal nos fatores de risco associados ao animal, bem como na utilização da vacina Escherichia coli J5 na imunização de fêmeas bovinas leiteiras.

Mastites causadas por coliformes

As bactérias gram-negativas são os agentes etiológicos mais isolados em casos clínicos de mastite aguda. O termo "coliforme" é frequentemente utilizado para se referir às mastites causadas por bactérias gram-negativas da família Enterobacteriaceae, sendo estas: Escherichia coli, Klebsiella sp e Enterobacter sp (HOGAN \& SMITH, 2003).

A transmissão dessas bactérias entre animais, isto é, de glândulas mamárias infectadas para sadias, parece mínima, se comparada à constante exposição ambiental. Devido a isso, esses microorganismos são considerados patógenos ambientais. Tais patógenos estão amplamente difundidos no ambiente das vacas leiteiras, sendo habitantes comuns do trato gastrointestinal e podendo ser encontrados ainda no solo e na água (HOGAN \& SMITH, 2003).

Apesar da adoção de certas medidas de manejo serem capazes de reduzir o número de IIM causadas por patógenos contagiosos, vários estudos demonstraram que a incidência de mastite causada por bactérias gram-negativas se manteve constante ou aumentou nos últimos anos. Estudos avaliando a incidência da mastite clínica em rebanhos com altas e baixas CCS no tanque de refrigeração indicaram um grande aumento na incidência de mastite clínica após redução na CCS do tanque (de 250.000 células $\mathrm{mL}^{-1}$ para 150.000 células $\mathrm{mL}^{-1}$ ), sendo a $\boldsymbol{E}$. coli o principal patógeno isolado (MILTENBURG et al.,1996; GREEN et al., 2007).

A mastite por coliformes caracteriza-se por alta incidência de casos clínicos, geralmente, de curta duração, com manifestação sistêmica e maior frequência nos momentos pré e pós-parto imediato, coincidindo com o período de imunossupressão (BURVENICH et al., 2003). Dessa forma, os prejuízos decorrentes dos casos clínicos de mastite por coliformes incluem desde a redução na produção de leite até a morte do animal, em casos mais severos, o que corresponde a cerca de $10 \%$ do total de casos (BRADLEY \& GREEN, 2000; GREEN et al., 2007; CHANETON et al.,2008).

\section{A bactéria Escherichia coli}

A $\boldsymbol{E}$. coli é uma bactéria gram-negativa, fermentadora de lactose e aeróbia facultativa. Sua parede celular é composta por uma camada de lipopolissacarídeos (LPS), a qual é formada por três camadas: uma interna, hidrofóbica, composta do lipídeo A (núcleo lipopolissacarídeo), uma média composta de oligossacarídeos e uma externa composta de polissacarídeos hidrofílicos, onde se localizam os antígenos O e K (HOGAN \& SMITH, 2003). Baseada nas diferenças antigênicas das estruturas do antígeno-O, antígeno-K (capsular) e antígeno- $\mathrm{H}$ (flagelar), as cepas de $\boldsymbol{E}$. coli podem ser divididas em sorotipos ou sorovares O:H:K (LEHTOLAINEN et al., 2003), sendo, atualmente, conhecidos mais de 700 tipos antigênicos (BURVENICH et al., 2007).

A $\boldsymbol{E}$. coli produz fatores de virulência necessários à colonização, infecção e proteção do agente contra os mecanismos de defesa do animal, estando esses fatores envolvidos na patogenia da mastite. Tais fatores incluem toxinas, adesinas, proteínas secretadas nas células do animal, cápsula de polissacarídeo e antígeno-O (BURVENICH et al., 2003).

O fator de virulência mais importante da E. coli é o LPS. Essa endotoxina, liberada durante o crescimento e destruição da bactéria, é uma moléculachave para os sinais de inflamação locais e sistêmicos que acompanham a mastite por gram-negativas. $\mathrm{O}$ LPS protege o organismo invasor contra as defesas 
celulares e humorais do sistema imune do animal, além de exibir uma grande variedade de atividades biológicas, direta ou indiretamente, envolvidas na patogenia do choque endotóxico (OISHI et al., 1992).

$\mathrm{Na}$ maioria dos casos, a bactéria não coloniza o parênquima mamário, porém certas cepas são capazes de invadir e aderir ao epitélio mamário, causando IIM crônicas e casos recorrentes de mastite clínica. BRADLEY \& GREEN (2000) demonstraram a habilidade da $\boldsymbol{E}$. coli em persistir na glândula mamária e permanecer em latência durante o período seco, causando casos clínicos de mastite apenas no início da lactação.

Segundo PASSEY et al. (2007), E. coli pode persistir no interior da glândula mamária por até 100 dias, sendo tal fenômeno identificado como importante contribuinte na dinâmica da incidência de casos clínicos de mastite por esse agente. Aproximadamente, $71 \%$ de todas as mastites clínicas por coliformes nos 100 primeiros dias de lactação são de quartos que se encontram previamente infectados, no período seco, com o mesmo agente causador da mastite clínica (BRADLEY \& GREEN, 2000).

Durante a multiplicação da bactéria ou após sua destruição, há intensa liberação de LPS. Uma vez liberada, a endotoxina atua aumentando a quimiotaxia de neutrófilos, bem como seu recrutamento do sangue para a glândula mamária, iniciando uma complexa cascata de eventos imunológicos que desencadeiam os sinais locais e sistêmicos da inflamação. Após a migração, os neutrófilos iniciam a fagocitose de células bacterianas, a qual é aumentada pela opsonização, em especial, pela IgG e IgM (BURVENICH et al., 2007).

O aumento da CCS no leite, observado na mastite por $\boldsymbol{E}$. coli, reflete esse recrutamento intenso de neutrófilos do sangue para o leite, em resposta às citocinas proinflamatórias (principalmente TNF- $\alpha$, IL-1 e IL-8), secretadas por macrófagos mamários patógeno-ativados, células epiteliais e células endoteliais (RIOLLET et al., 2000).

Fatores de risco associados ao animal na mastite por E. coli.

Segundo BRADLEY \& GREEN (2004), as IIM presentes durante o período seco podem ser dividas entre infecções pré-existentes, ou seja, aquelas que foram adquiridas durante a lactação e continuaram durante o período seco, e novas infecções, isto é, aquelas que foram adquiridas entre a secagem e o parto.

A probabilidade de ocorrência de uma nova IIM durante o período seco é influenciada pela taxa de exposição à patógenos potenciais (por exemplo, do ambiente), fatores que afetam a susceptibilidade individual do animal à infecção (DINGWELL et al., 2004) e à eficiência da proteção, oferecida por intervenções medicamentosas para vacas secas (ROBERT et al., 2006).

A fase de maior risco a novas IIM durante o período seco é a fase inicial, especificamente, as três primeiras semanas após a secagem, que corresponde à chamada fase de involução ativa. Nesse momento, a extração do leite é interrompida, bem como os mecanismos de desinfecção dos tetos (pré e pósdipping), interrompendo a retirada contínua das bactérias do canal do teto, propiciando, assim, o aumentando da carga bacteriana local (BURVENICH et al., 2003). Com a estase do leite, ocorre um aumento na pressão interna da glândula mamária, nos primeiros dias após a secagem, resultando na dilatação do teto e, consequentemente, favorecendo a penetração bacteriana através do esfíncter (GREEN et al., 2002). A entrada de patógenos nesse período também é facilitada pela ausência de uma barreira física (tampão de queratina), formada entre o $7^{\circ}$ ao $10^{\circ}$ dia pós secagem (BRADLEY \& GREEN, 2004; DINGWELL et al., 2004).

Adicionalmente, níveis leucocitários satisfatórios, na glândula mamária, somente são alcançados após o oitavo dia da secagem. Entretanto, tais células podem ainda apresentar atividade fagocitária sobre as bactérias diminuída por fagocitarem glóbulos de gordura e debris celulares, presentes em maior quantidade (SORDILLO, 2005; BURVENICH et al., 2007).

Há ainda uma relação citrato/lactoferrina muito alta, o que diminui a ação da lactoferrina (BURVENICH et al., 2007). Essa proteína apresenta capacidade bacteriostática por se ligar aos íons de ferro, indisponibilizando-os ao crescimento bacteriano, além de possuir atividade bactericida pela interação direta com as porções catiônicas N-terminais dos compostos bacterianos (CHANETON et al., 2008).

Outra fase de alta susceptibilidade é observada no final do período seco. Nesse momento, acontece nova fase de transição na glândula mamária em resposta à ação hormonal do fim da gestação (SORDILLO, 2005). Há diminuição nos níveis de lactoferrina e aumento nos níveis de citrato, devido à retomada da síntese de leite (BURVENICH et al., 2007). O número de leucócitos não só diminui como também sua capacidade fagocítica, pelo aumento nas concentrações de gordura e caseína. $\mathrm{O}$ estresse do parto estimula a produção de corticosteroides que promovem diminuição no número, distribuição e função de leucócitos no sangue, além de diminuição 
na migração de neutrófilos no período pós-parto (BURTON \& ERSKINE, 2003).

Vacas no periparto são especialmente suscetíveis à mastite, devido à imunossupressão (BURVENICH et al., 2003). A falha na montagem de uma resposta imune satisfatória pode estar associada com mudanças no fenótipo de células mononucleares do sangue durante o período pré-parto. Tal mudança pode resultar em menor recrutamento de polimorfonucleares (PMN) para a glândula mamária, com significativa redução na eficiência da eliminação de patógenos invasores (BURTON \& ERSKINE, 2003).

SHUSTER et al. (1996) observaram que vacas no pós-parto imediato desenvolviam casos mais severos de mastite clínica, os autores atribuíram à diferença de intensidade dos sinais clínicos à inabilidade de vacas no pós-parto imediato em controlar o crescimento bacteriano nas primeiras horas após a inoculação. Esses achados indicam que a baixa resposta de PMN pode ser importante em ditar a intensidade da doença clínica.

Aparentemente, tanto as contagens de células iniciais, quanto a velocidade de migração dos leucócitos para a glândula mamária, são importantes na defesa da vaca contra mastite clínica. No entanto, outros fatores não devem ser negligenciados, tais como o status nutricional, em particular, a suplementação com vitamina E e selênio (SORDILHO, 2005), assim como o balanço energético negativo, os quais têm demonstrado grande influência na velocidade de recrutamento e migração de neutrófilos (SURIYASATHAPORN et al., 1999).

A probabilidade de infecção pode ser influenciada ainda, pela interação entre fatores como: status da infecção da vaca na secagem, tendência individual do animal a se curar de uma nova infecção, estratégias de tratamento e presença de infecção ao parto (BRADLEY \& GREEN, 2000; GREEN et al., 2007).

\section{A Vacina $\boldsymbol{E}$. coli J5}

Pelo fato de o período seco e pós-parto serem períodos de grande risco de IIM, é necessário que se estabeleçam estratégias de controle (SORDILLO et al., 1997). Uma das formas mais utilizadas é a administração intramamária de formulações, contendo antibióticos para vacas secas ao término da lactação. Essa medida possui, basicamente, duas funções: remover IIM pré-existentes e prevenir novas infecções durante o período seco.

Assume-se que essa terapia não apresenta alta eficácia contra coliformes, uma vez que a maioria dos antibióticos disponíveis não tem ação contra bactérias gram-negativas e, portanto, não possuem grande eficácia contra novas IIM que se iniciam no período pré-parto (HALASA et al., 2009).

Sendo assim, outra forma de controle para mastites causadas por $\boldsymbol{E}$. coli, seria a associação da terapia de vaca seca a mecanismos de aumento da resposta imune do animal, como, por exemplo, o emprego da vacina $\boldsymbol{E}$. coli J5 (BURVENICH et al., 2007; WILSON et al., 2007a; GENTILINI et al., 2012; GENTILINI et al., 2013).

Para a imunização de vacas contra as mastites causadas por coliformes, duas cepas mutantes de bactérias têm sido utilizadas em preparações comerciais: Escherichia coli O111:B4 (denominada J5) e Salmonella typhimurium Re-17 (WILSON \& GONZÁLEZ, 2003). A cepa J5, presente na maioria das vacinas comerciais, possui um antígeno do núcleo relativamente exposto - um lipopolissacarídeo comum às demais bactérias gram-negativas - capaz de estimular a resposta imune do animal contra esses patógenos (CHAIYOTWITTAYAKUN et al., 2004).

Os neutrófilos do leite são a principal defesa imunológica quando os patógenos causadores de mastite adentram o canal do teto (SORDILLO et al., 2005). Entretanto, caso essa infecção não seja rapidamente debelada, permitindo que o LPS e lipoproteínas ganhem a corrente sanguínea, os anticorpos presentes no soro sanguíneo capazes de bloquear e neutralizar essas toxinas precisam estar disponíveis. Dessa forma, o maior objetivo na vacinação, como prevenção a mastites por coliformes, é atingir altos níveis de anticorpos efetivos anticoliformes e antitoxinas no leite, no sangue, bem como ao redor do canal do teto (BURVENICH et al., 2007).

Nos bovinos, a glândula mamária divide linfócitos com o sistema imune periférico (KHERLI \& HARP, 2001). Em função disso, é importante que as vacinas possuam capacidade de estimular os linfócitos $\mathrm{B}$ e $\mathrm{T}$, os quais devem atingir os linfonodos rapidamente para divisão e diferenciação em células secretoras de anticorpos e, então, migrar para glândula mamária (SORDILLO, 2002). Assim, a grande maioria dos anticorpos protetores deve ser oriunda do sangue, ao menos nas fases iniciais da resposta. Esses anticorpos atingem o leite por meio de transporte imuno-mediado através das células epiteliais mamárias (VERBEET et al., 1995), ou por transudação passiva durante o edema, que se segue após a IIM.

Algumas classes (isotipos) de anticorpos funcionam melhor que outros em facilitar a 
eliminação das bactérias do úbere pelos neutrófilos, assim como na neutralização do LPS e lipoproteínas que escapem do leite para o sangue. Esses anticorpos são particularmente importantes no período préparto, momento em que os neutrófilos precisam de um suporte extra, pois estão deficientes em termos de função (DETILLEUX et al., 1995).

Nesse contexto, o grande desafio no desenvolvimento de vacinas efetivas contra as mastites causadas por coliformes foi descobrir um imunógeno capaz de induzir uma reação protetora cruzada, realizada por anticorpos, contra uma grande variedade de coliformes, os quais deveriam proliferarse bem no leite e eliminar o LPS e lipoproteínas da corrente sanguínea de vacas no periparto (KHERLI \& HARP, 2001). No final da década de 1980, ocorreu uma grande reviravolta nos estudos sobre vacinas contra mastites causadas por coliformes, com a introdução de bacterinas contendo cepas mutantes rugosas de bactérias gram-negativas (YANCY, 1999). Em 1984, NELLS \& NISWANDER (1984) descobriram que a maioria das bactérias gram-negativas dividem a estrutura interna do LPS (lipídeo A), a qual, além de patogênica, é extremamente antigênica, possuindo reação cruzada com o LPS, derivado de uma grande variedade de espécies de bactérias gram-negativas.

A Escherichia coli (O111:B4) J5 é uma cepa mutante rugosa que possui a cadeia "O" de polissacarídeos incompleta, expondo a metade homóloga do antígeno do núcleo do LPS (BRADLEY \& GREEN, 2004). A exposição deste, estimula a produção de imunoglobulinas que possuem reação cruzada contra os antígenos de núcleo de outras bactérias, resultando em imunidade associada à proteção contra uma variedade de gêneros e cepas de bactérias (WILSON et al., 2008). A utilização de $\boldsymbol{E}$. coli J5 aumenta os títulos séricos e do leite de anticorpos específicos contra o LPS de $\boldsymbol{E}$. coli $\mathrm{J} 5$, intensificando sua opsonização, bem como reduzindo a incidência e intensidade dos casos clínicos de mastite por coliformes (GONZÁLEZ et al., 1989; BAUMGARTNER et al., 1991; HOGAN et al., 1995). No entanto, os mecanismos, nos quais a imunização com $\boldsymbol{E}$. coli J5 realmente atuam, ainda não foram completamente esclarecidos (DOSOGNE et al., 2002).

Estudos indicam que, durante a fase de crescimento da $\boldsymbol{E}$. coli, o antígeno do núcleo é exposto, momento em que $\mathrm{IgM}, \mathrm{IgG}_{1}$ e $\mathrm{IgG}_{2}$, se aderem à parede celular bacteriana (DOSOGNE et al., 2002). Um mecanismo adicional de ação envolve a neutralização de endotoxinas por anticorpos, após processamento dos produtos da parede celular bacteriana pelos fagócitos do úbere, atribuindo às endotoxinas menor toxicidade e aumentando a taxa de eliminação hepática (SMITH et al., 1999).

O valor potencial da imunização de vacas leiteiras, utilizando bacterinas com antígeno de núcleo exposto, ficou evidente após a observação por TYLER et al. (1988) de que vacas, que possuíam naturalmente títulos de $\mathrm{IgG}_{1}$ contra $\boldsymbol{E}$. coli J5 menores que 1:240, apresentavam risco cinco vezes maior de ocorrência de caso clínico de mastite por coliformes, se comparadas às vacas com títulos maiores que 1:240. TOMITA et al. (1998) e SMITH et al. (1999) observaram que vacas vacinadas possuem maiores títulos de anticorpos que reconhecem o núcleo LPS de $\boldsymbol{E}$. coli J5 nas secreções mamárias, apresentando assim menor risco de ocorrência de IIM durante o período seco e pós-parto.

Diversos estudos têm verificado redução na ocorrência de casos clínicos em vacas vacinadas, comparadas às não vacinadas, em cerca de $80 \%$ (GONZÁLEZ et al., 1989), 70\% (CULLOR, 1991), $75 \%$ (HOGAN et al., 1995) e 66\% (GENTILINI et al., 2013). Além disso, observou-se menor intensidade do quadro clínico no grupo vacinado (GONZÁLEZ et al., 1989; CULLOR et al., 1991; CLARK \& ROECKEL, 1994; GENTILINI et al., 2013). Tais resultados demonstram a eficiência da vacina $\boldsymbol{E}$. coli $\mathrm{J} 5 \mathrm{em}$ proteger contra a ocorrência e intensidade de casos clínicos de mastite, oriundos de infecções naturais por bactérias gram-negativas, em vacas leiteiras, durante os três primeiros meses de lactação.

Estima-se que a duração e intensidade dos casos clínicos estão, positivamente, correlacionadas com a contagem bacteriana no leite, a qual também é responsável por sintomas sistêmicos, como o aumento da temperatura retal, frequência cardíaca, frequência respiratória e diminuição mais acentuada do apetite em animais não vacinados (WENZ et al., 2006). HOGAN et al. (1995; 1999; 2005) demonstraram que a vacinação se revelou eficaz em reduzir o pico de contagem bacteriana em quartos infectados e, consequentemente, a duração das IIM e dos sinais clínicos de mastite em $25 \%$ e $50 \%$, respectivamente, quando comparados grupos vacinados e não vacinados. Essa redução na contagem bacteriana se deve ao aumento nas concentrações séricas e do leite, de $\operatorname{IgG}$ e IgM, as quais agem diretamente nos antígenos da superfície de bactérias gram-negativas, promovendo neutralização do LPS e aumento na fagocitose pelos neutrófilos.

De acordo com TOMITA et al. (2000), a redução na intensidade dos casos clínicos é atribuída 
não só à eliminação bacteriana, mas também à neutralização do LPS, devido ao elevado título de anticorpos contra os antígenos internos do LPS de E. coli J5. WILSON et al. (2007b) concluíram que a vacinação com $\boldsymbol{E}$. coli $\mathrm{J} 5$ esteve associada à maior eliminação de bactérias da glândula mamária e menor redução na produção de leite após o desafio.

Com relação à CCS, a avaliação da eficiência da vacina $\boldsymbol{E}$. coli J5 é bastante complexa e apenas observada durante o caso clínico de mastite. HOGAN et al. (2005) observaram que a vacinação esteve associada à menor CCS, cerca de 15 horas após o desafio. WILSON et al. (2007b) relatam que, após o desafio, a CCS do leite de vacas vacinadas com $\boldsymbol{E}$. coli J5 foi em média de 500.000cél $\mathrm{ml}^{-1}$ contra 5.000.000cél $\mathrm{ml}^{-1}$ no grupo controle. Entretanto, HOGAN et al. (1999) e GENTILINI et al. (2013) não verificaram associação entre a imunização com E. coli J5 em fêmeas bovinas leiteiras e a magnitude da resposta da CCS. Tais resultados podem estar relacionados ao fato da mastite clínica por $\boldsymbol{E}$. coli estar associada ao padrão denominado "rápida recuperação", isto é, rápida elevação da CCS com rápido declínio desta.

No que se refere à produção de leite, GRÖHN et al. (2004) demonstraram existir uma redução tanto em vacas quanto em novilhas, após um quadro clínico de mastite por $\boldsymbol{E}$. coli. Segundo SCHUKKEN et al. (2009), a produção original só é completamente recuperada durante a lactação subsequente. Achados relacionados à produção de leite em animais vacinados com $\boldsymbol{E}$. coli J5 indicam que a vacina parece evitar a diminuição na produção desses animais. Em estudo conduzido por WILSON et al. (2008), vacas não vacinadas produziram menos leite após o desafio, permanecendo assim durante toda lactação. Resultados semelhantes foram obtidos por GENTILINI et al. (2013). Em contrapartida, vacas vacinadas com $\boldsymbol{E}$. coli J5 produziram em média $2 \mathrm{~kg}$ de leite/dia a mais do que vacas não vacinadas. Esse resultado também foi observado em novilhas vacinadas, que produziram em média $3 \mathrm{~kg}$ de leite $\operatorname{dia}^{-1}$ a mais em relação a novilhas não vacinadas (GENTILINE et al., 2012).

\section{CONCLUSÃO}

$\mathrm{O}$ início do período seco, bem como seu final, representam dois momentos de extrema importância na definição da ausência ou não de um quadro de mastite decorrente da ação de patógenos ambientais no pós-parto imediato. Nesse período, vários fenômenos fisiológicos coexistentes exigem cuidados e manejo específico a fim de reduzir os desafios e fatores de risco enfrentados pelos animais.

O emprego da terapia para vacas secas apresenta bons resultados frente a infecções por bactérias gram-positivas. Entretanto, ao se tratar de germes ambientais, esta perde eficácia, sendo necessária a associação com outros métodos, como a utilização da vacina Escherichia coli J5.

A vacina Escherichia coli J5 é capaz de reduzir a ocorrência, intensidade e duração de casos clínicos de mastite por Escherichia coli, sendo também observada uma maior produção de leite nos animais vacinados. Entretanto, ainda é controverso seu papel na redução da CCS.

\section{REFERÊNCIAS}

BAUMGARTNER, J.D. et al. Antibodies to lipopolysaccharides after immunization of humans with the rough mutant Escherichia coli J5. Journal of Infectious Diseases, v.163, n.4, p.769772, 1991. Disponível em: <http://jid.oxfordjournals.org/ content/163/4/769.short $>$. Acesso em: 27 nov. 2013. doi: 10.1093/ infdis/163.4.769.

BRADLEY, A.J.; GREEN, M.J. A study of the incidence and significance of intramammary enterobacteriacel infections acquired during the dry period. Journal of Dairy Science, v.83, n.9, p.1957-1965, 2000. Disponível em: <http://www.sciencedirect. com/science/article/pii/S0022030200750727>. Acesso em: 27 nov. 2013. doi: 10.3168/jds.S0022-0302(00)75072-7.

BRADLEY, A.J.; GREEN, M.J. The importance of non-lactating period in the epidemiology of intrammamary infection and strategies for prevention. Veterinary Clinics of North America: Food Animal Practice. v.20, n.3, p.547-568, 2004. Disponível em: $<\mathrm{http}$ ://europepmc.org/abstract/MED/15471624/reload=0;jsession $\mathrm{id}=3 \mathrm{cClObPGO} 1 \mathrm{vNZuinTr1k} .10>$. Acesso em: 27 nov. 2013. doi: 10.1016/j.cvfa.2004.06.010.

BURTON, J.L.; ERSKINE, R.J. Immunity and mastitis some new ideas for an old disease. Veterinary Clinics of North America: Food Animal Practice, v.19, p.1-45, 2003. Disponível em: $<$ http://cytalabs.com/publicaciones2011/Immunity $\% 20$ and $\% 20$ mastitis \%20Some $\% 20$ new $\% 20$ ideas $\% 20$ for $\% 20$ an $\% 20$ old $\% 20$ disease.pdf $>$. Acesso em: 27 nov. 2013. doi: 10.1016/07490720(02)00073-7.

BURVENICH, C. et al. Severity of E. coli mastitis is mainly determined by cow factors. Veterinary Research, v.34, p.521564, 2003. Disponível em: <https://biblio.ugent.be/input/downlo ad func $=$ downloadFile $\&$ recordOId $=209724 \&$ fileOId $=984758>$. Acesso em: 27 nov. 2013. doi: 10.1051/vetres:2003023.

BURVENICH, C. et al. Cumulative physiological events influence the inflammatory response of bovine udder to Escherichia coli infections during the transition period. Journal of Dairy Science, v.90, p.E39-E54, 2007. Disponível em: <http://www. journalofdairyscience.org/article/S0022-0302(07)72059-3/ fulltext>. Acesso em: 27 nov. 2013. doi: 10.3168/jds.2006-696.

CHAIYOTWITTAYAKUN, A. et al. Hyperimmunization of steers with J5 Escherichia coli bacterin: effects on isotype-specific serum 
antibody responses and cross reactivity with heterogeneous gramnegative bacteria. Journal of Dairy Science, v.87, n.10, p.33753385, 2004. Disponível em: <http://www.journalofdairyscience. org/article/S0022-0302(04)73473-6/abstract>. Acesso em: 27 nov. 2013. doi: 10.3168/jds.S0022-0302(04)73473-6.

CHANETON, L. et al. Relationship between milk lactoferrin and etiological agent in the mastitic bovine mammary gland. Journal of Dairy Science, v.91, n.5, p.1865-1873, 2008. Disponível em: <http://www.sciencedirect.com/science/article/pii/ S0022030208712232>. Acesso em: 27 nov. 2013. doi: 10.3168/ jds.2007-0732.

CLARK, P.; Van ROEKEL, D. Efficacy of an Escherichia coli bacterin for the control of coliform mastitis in dairy cows. Agripractice, v.15, p.19-25, 1994.

CULLOR, J.S. The Escherichia coli J5 vaccine: investigating a new tool to combat mastitis. Veterinary Medicine, v.86, p.836-844, 1991.

DETILLEUX, J.C. et al. Study of immunological dysfunction in periparturient Holstein cattle selected for high and average milk production. Veterinary Immunology and Immunopathology, v.44, n.3-4, p.251-267, 1995. Disponível em: <http://www. sciencedirect.com/science/article/pii/0165242794053029>. Acesso em: 27 nov. 2013. doi: 10.1016/0165-2427(94)05302-9.

DINGWELL, R.T. et al. Association of cow and quarter-level factors at drying off with new intramammary infections during the dry period. Preventive Veterinary Medicine, v.63, n.1-2, p.7589, 2004. Disponível em: <http://www.sciencedirect.com/science/ article/pii/S0167587704000510>. Acesso em: 27 nov. 2013. doi: 10.1016/j.prevetmed.2004.01.012.

DOSOGNE, H. et al. Potencial mechanism of action of J5 vaccine in protection against severe bovine coliform mastitis. Veterinary Research, v.33, n.1, p.1-12, 2002. Disponível em: $<$ https://biblio. ugent.be/input/download? func $=$ downloadFile \& recordOId $=149$ 254\&fileOId $=984948>$. Acesso em: 27 nov. 2013. doi: 10.1051/ vetres:2001001.

GENTILINI, M.B. et al. Utilização da vacina Escherichia coli J5 na imunização de novilhas leiteiras contra mastites causadas por $\boldsymbol{E}$. coli. Arquivo Brasileiro de Medicina Veterinária e Zootecnia, v.64, n.1, p.67-74, 2012. Disponível em: <http://www.scielo.br/ pdf/abmvz/v64n1/a11v64n1.pdf>. Acesso em: 27 nov. 2013.

GENTILINI, M.B. et al. Utilização da vacina Escherichia coli J5 na imunização de vacas leiteiras contra mastites causadas por E. coli. Pesquisa Veterinária Brasileira, v.33, n.3, p.291-298, 2013. Disponível em: <http://www.pvb.com.br/pdf_artigos/13-042013_15-57Vet\%201372_2586\%20LD.pdf>. Acesso em: 27 nov. 2013.

GONZÁLEZ, R.J. et al. Prevention of clinical coliform mastitis in dairy cows by a mutant Escherichia coli vaccine. Canadian Journal of Veterinary Research, v.53, n.3, p.301-305, 1989. Disponível em: <http://www.ncbi.nlm.nih.gov.ez27.periodicos. capes.gov.br/pmc/articles/PMC1255715/?page=1>. Acesso em: 27 nov. 2013

GREEN, M.J. et al. Influence of dry period bacterial intramammary infection on clinical mastitis in dairy cows. Journal of Dairy Science, v.85, n.10, p.2589-2599, 2002. Disponível em: <http:// www.sciencedirect.com/science/article/pii/S0022030202743439>. Acesso em: 27 nov. 2013. doi: 10.3168/jds.S0022-0302(02)74343-9.
GREEN, M.J. et al. Cow, farm, and management factors during the dry period that determine the rate of clinical mastitis after calving. Journal of Dairy Science, v.90, n.8, p.3764-3776, 2007. Disponível em: <http://www.sciencedirect.com/science/article/pii/ S0022030207718337>. Acesso em: 27 nov. 2013. doi: 10.3168/ jds.2007-0107.

GRÖHN, Y.T. et al. Effect of pathogen-specific clinical mastitis on milk yield in dairy cows. Journal of Dairy Science, v.87, n.10, p.3358-3374, 2004. Disponível em: <http://www. journalofdairyscience.org/article/S0022-0302(04)73472-4/ abstract>. Acesso em: 27 nov. 2013. doi: 10.3168/jds.S00220302(04)73472-4.

HALASA, T. et al. Meta-analysis of dry cow management for dairy cattle. Part 1 . Protection against new intramammary infections. Journal of Dairy Science, v.92, n.7, p.3134-3149, 2009. Disponível em: <http://www.journalofdairyscience.org/ article/S0022-0302(09)70630-7/abstract>. Acesso em: 27 nov. 2013. doi: $10.3168 /$ jds.2008-1740.

HOGAN, J.S. et al. Effects of an Escherichia coli J5 vaccine on mild clinical coliform mastitis. Journal of Dairy Science, v.78, n.2, p.285-290, 1995. Disponível em: <http://www.sciencedirect. com/science/article/pii/S002203029576636X $>$. Acesso em: 27 nov. 2013. doi: 10.3168/jds.S0022-0302(95)76636-X.

HOGAN, J.S. et al. Efficacy of an Escherichia coli J5 bacterin administered to primigravid heifers. Journal of Dairy Science, v.82, n.5, p.939-943, 1999. Disponível em: <http://www. journalofdairyscience.org/article/S0022-0302(99)75312-9/ abstract>. Acesso em: 27 nov. 2013. doi: 10.3168/jds.S00220302(99)75312-9.

HOGAN, J.; SMITH, K.L. Coliform mastitis. Veterinary Research, v.34, n.5, p.507-519, 2003. Disponível em: <http:// dx.doi.org/10.1051/vetres:2003022>. Acesso em: 27 nov. 2013. doi: $10.1051 /$ vetres:2003022.

HOGAN, J.S. et al. Effects of adjuvants on safety and efficacy of an Escherichia coli J5 bacterin. Journal of Dairy Science, v.88, n.2, p.534-542, 2005. Disponível em: <http://www. journalofdairyscience.org/article/S0022-0302(05)72715-6/ abstract>. Acesso em: 27 nov. 2013. doi: 10.3168/jds.S00220302(05)72715-6

KHERLI, M.E.; HARP, J.A. Immunity in the mammary gland. Veterinary Clinics of North America: Food Animal Practice, v.17, n.3, p.495-516, 2001.

LEHTOLAINEN, T. et al. Effect of intramammary Escherichia coli Endotoxin in early- vs. late-lactating dairy cows. Journal of Dairy Science, v.86, n.7, p.2327-2333, 2003. Disponível em: <http:// www.journalofdairyscience.org/article/S0022-0302(03)73825-9/ abstract>. Acesso em: 27 nov. 2013. doi: 10.3168/jds.S00220302(03)73825-9.

MILTENBURG, J.D. et al. Incidence of clinical mastitis in a random sample of dairy herds in the southern Netherlands. Veterinary Record, v.139, n.9, p.204-207, 1996. Disponível em: $<$ http://veterinaryrecord.bmj.com/content/139/9/204.abstract>. Acesso em: 27 nov. 2013. doi: 10.1136/vr.139.9.204.

NELLS, M.; NISWANDER, C. Mouse monoclonal antibodies reactive with J5 lipopolysaccharide exhibit extensive serological 
cross-reactivity with a variety of gram-negative bacteria. Infection and Immunity, v.46, n.3, p.677-681, 1984. Disponível em: <http:// www.ncbi.nlm.nih.gov/pmc/articles/PMC261596/?page $=1>$. Acesso em: 27 nov. 2013.

OISHI, K. et al. Antibacterial and protective properties of monoclonal antibodies reactive with Escherichia coli O111:B4 lipopolysaccharide: relation to antibody isotype and complementfixing activity. Journal of Infectious Diseases, v.165, n.1, p.34-45, 1992. Disponível em: <http://jid.oxfordjournals.org/ content/165/1/34.full.pdf >. Acesso em: 27 nov. 2013.

PASSEY, S. et al. Escherichia coli isolated from bovine mastitis invade mammary cells by a modified endocytic pathway. Veterinary Microbiology, v.130, n.1-2, p.151-164, 2007. Disponível em: <http://www.sciencedirect.com/science/article/pii/ S0378113508000059>. Acesso em: 27 nov. 2013. doi: 10.1016/j. vetmic.2008.01.003.

RIOLLET, C.P. et al. Kinetics of cells and cytokines during immune-mediated inflammation in the mammary gland of cows systematically immunized with Staphylococcus aureus alpha-toxin. Inflammation Research, v.49, p.486496, 2000. Disponível em: <http://link.springer.com/content/ pdf/10.1007\%2Fs000110050621>. Acesso em: 27 nov. 2013. doi: $10.1007 / \mathrm{s} 000110050621$.

ROBERT, A. et al. Incidence of intramammary infections during the dry period without or with antibiotic treatment in dairy cows. Veterinary Research, v.37, n.1, p.2548, 2006. Disponível em: <http://www.vetres.org/index. php?option $=$ com_article \&access $=$ doi $\&$ doi $=10.1051 /$ vetres: $2005047 \&$ Itemid=129>. Acesso em: 27 nov. 2013. doi: DOI: $10.1051 /$ vetres:2005047.

SCHUKKEN, Y.H. et al. Effects of repeated gram-positive and gram-negative clinical mastitis episodes on milk yield loss in Holstein dairy cows. Journal of Dairy Science, v.92, n.7, p.30913105, 2009. Disponível em: <http://www.journalofdairyscience. org/article/S0022-0302(09)70626-5/abstract>. Acesso em: 27 nov. 2013. doi: $10.3168 /$ jds.2008-1557.

SHUSTER, D.E. et al. Bacterial growth, inflammatory cytokine production, and neutrophil recruitment during coliform mastitis in cows, within ten days after calving, compared with cows at midlactation. American Journal of Veterinary Research, v.57, p.1569-1575, 1996

SMITH, J.L. et al. Efficacy of intramammary immunization with Escherichia coli J5 bacterin. Journal of Dairy Science, v.82, n.12, p.2582-2588, 1999. Disponível em: <http://www. journalofdairyscience.org/article/S0022-0302(99)75513-X/ abstract>. Acesso em: 27 nov. 2013. doi: 10.3168/jds.S00220302(99)75513-X.

SORDILLO, L.M. et al. Immunobiology of the mammary gland. Journal of Dairy Science, v.80, n.8, p.1851-1865, 1997. Disponível em: <http:/www.journalofdairyscience.org/article/ S0022-0302(97)76121-6/abstract>. Acesso em: 27 nov. 2013. doi: 10.3168/jds.S0022-0302(97)76121-6.

SORDILLO, L.M.; STREICHER, K. Mammary gland immunity and mastitis susceptibility. Journal of Mammary Gland Biology and Neoplasia, v.7, n.2, p.135-146, 2002. Disponível em: <http:// pages.usherbrooke.ca/infosbio/PSL705/bibliographie/sordillo. pdf>. Acesso em: 27 nov. 2013.
SORDILLO, L. Factors affecting mammary gland immunity and mastitis susceptibility. Livestock Production Science, v.98, n.12, p.89-99, 2005. Disponível em: <http://www.sciencedirect.com/ science/article/pii/S0301622605002885>. Acesso em: 27 nov. 2013. doi: 10.1016/j.livprodsci.2005.10.017.

SURIYASATHAPORN, W. et al. Beta-hydroxybutyrate levels in peripheral blood and ketone bodies supplemented in culture media affect the in vitro chemotaxis of bovine leukocytes. Veterinary Immunology and Immunopathology, v.68, n.2-4, p.177-186, 1999. Disponível em: <http://www.sciencedirect.com/science/ article/pii/S0165242799000173>. Acesso em: 27 nov. 2013. doi: 10.1016/S0165-2427(99)00017-3.

TOMITA, G.M. et al. Influence of route of vaccine administration against experimental intramammary infection caused by Escherichia coli. Journal of Dairy Science, v.81, n.8, p.21592164, 1998. Disponível em: <http://www.journalofdairyscience. org/article/S0022-0302(98)75793-5/abstract>. Acesso em: 27 nov. 2013. doi: 10.3168/jds.S0022-0302(98)75793-5.

TOMITA, G.M. et al. A comparison of two commercially available Escherichia coli J5 vaccines against $\boldsymbol{E}$. coli intramammary challenge. Journal of Dairy Science, v.83, n.10, p.2276-2281, 2000. Disponível em: <http:/www.journalofdairyscience.org/ article/S0022-0302(00)75112-5/abstract>. Acesso em: 27 nov. 2013. doi: 10.3168/jds.S0022-0302(00)75112-5.

TYLER, J. et al. Relationship between serological recognition of Escherichia coli O111: B4 (J5) and clinical coliform mastitis in cattle. American Journal of Veterinary Research, v.49, p.19501954, 1988.

VERBEET, M.P. et al. Cloning and characterization of the bovine polymeric immunoglobulin receptor-encoding cDNA. Gene, v.164, n.2, p.329-333, 1995. Disponível em: <http://www. sciencedirect.com/science/article/pii/037811199500520G>. Acesso em: 27 nov. 2013. doi: 10.1016/0378-1119(95)00520-G.

WENZ, J.R. et al. Escherichia coli isolates serotypes, genotypes, and virulence genes and clinical coliform mastitis severety. Journal of Dairy Science, v.89, n.9, p.3408-3412, 2006. Disponível em: <http://www.journalofdairyscience.org/article/ S0022-0302(06)72377-3/abstract>. Acesso em: 27 nov. 2013. doi: 10.3168/jds.S0022-0302(06)72377-3.

WILSON, D.J.; GONZÁLEZ, N. Vaccination strategies for reducing clinical severity of coliform mastitis. Veterinary Clinics of North America: Food Animal Practice, v.19, p.187-197, 2003. Disponível em: <http://cytalabs.com/publicaciones2011/ Vaccination $\% 20$ strategies $\% 20$ for $\% 20$ reducing $\% 20$ clinical $\% 20$ severity $\% 20$ of $\% 20$ coliform $\% 20$ mastitis.pdf $>$. Acesso em: 27 nov. 2013.

WILSON, D.J. et al. Comparison of J5 vaccinates and controls for incidence, etiologic agent, clinical severity, and survival in the herd following naturally occurring cases of clinical mastitis. Journal of Dairy Science, v.90, n.9, p.4282-4288, 2007a. Disponível em: <http://www.journalofdairyscience.org/article/ S0022-0302(07)71888-X/abstract>. Acesso em: 27 nov. 2013. doi: $10.3168 /$ jds.2007-0160.

WILSON, D.J. et al. Milk and Serum J5-specific antibody responses, milk production change, and clinical effects following intramammary Escherichia coli challenge for J5 vaccine and control cows. Clinical and Vaccine Immunology, v.14, p.693- 
699, 2007b. Disponível em: < http://cvi.asm.org/content/14/6/693. short>. Acesso em: 27 nov. 2013.

WILSON, D.J. et al. Milk production change following clinical mastitis and reproductive performance compared among j5 vaccinated and control dairy cattle. Journal of Dairy Science, v.91, n.10, p.3869-3879, 2008. Disponível em: <http://www. journalofdairyscience.org/article/S0022-0302(08)71013-0/ abstract>. Acesso em: 27 nov. 2013. doi: 10.3168/jds.20081405 .

YANCY, R.J. Vaccines and diagnostic methods for bovine mastitis: facts and fiction. Advances in Veterinary Medicine, v.41, p.257-273, 1999. Disponível em: <http://www.sciencedirect. com/science/article/pii/S0065351999800202>. Acesso em: 27 nov. 2013. doi: 10.1016/S0065-3519(99)80020-2. 